INTERNATIONAL JOURNAL OF MULTIDisciplinARY RESEARCH AND ANALYSis

ISSN(print): 2643-9840, ISSN(online): 2643-9875

Volume 04 Issue 05 May 2021

DOI: 10.47191/ijmra/v4-i5-08, Impact Factor: 6.072

Page No.- $550-555$

\title{
COVID-19 And Smoking: A Cross-Sectional Study Done In Lebanon
}

\author{
Najwa Baassiry ${ }^{1}$, Marwa El-Hallak ${ }^{2}$, Ali Alkhatib ${ }^{3}$, Sami Tlais ${ }^{4}$, and Hassan S. HajjHussein ${ }^{5}$ \\ 1,2,3 Department of Nutrition and Food Sciences, School of Arts and Sciences, Lebanese International University, Beirut, Lebanon; \\ ${ }^{4,5}$ Department of Biological and Chemical Sciences, School of Arts and Sciences, Lebanese International University, Rayak, \\ Lebanon
}

ABSTRACT:

Background: to assess smoking habits and investigate any impact of smoking on COVID-19 susceptibility and symptom development.

Study design: a cross-sectional study.

Methods: A total of 1642 participants volunteered and took part in answering the questionnaire. Information about the level of knowledge on COVID-19, smoking habits, and COVID-19-related symptoms of participants were collected using an online questionnaire.

Results: The study revealed that a very high percentage of the Lebanese population, especially males, are smokers. Smoking was independent of age and level of education; however, we detected a shift in preference among the younger smokers from cigarette to shisha smoking. We did not detect any influence of smoking, level of education, or geographical location on the probability of contracting COVID-19. COVID-19 patients who are also shisha smokers were significantly more likely to experience severe body pain and speaking and moving difficulty compared to cigarette smokers. In addition, infected shisha smokers who used artificial coal as a burning agent were more likely to experience loss of smell and taste compared to those that used natural coal.

Conclusions: Shisha smokers, and especially those that use artificial coal, may be at a higher risk of developing more severe symptoms of COVID-19 and possibly other respiratory-related illnesses. The increased tendency of the younger generations to smoke shisha is alarming

Keywords- COVID-19, symptoms, smoking, shisha, cigarette, Lebanon

\section{INTRODUCTION}

Ever since the start of the Corona Virus Disease 2019 (COVID-19) pandemic, and up until April 5, 2021, more than 479,501 positive cases and 6409 deaths have been reported in Lebanon [1]. Tens of studies have been made worldwide trying to understand and clarify the correlation between smoking and the severity of COVID 19 symptoms [2-5]. A recent study looking at active smokers compared to non-smokers reported a doubling in the risk of developing severe COVID-19 infection [3]. Parallel results showed that smokers were 1.4 times more likely to develop severe symptoms of COVID-19 and approximately 2.4 times more likely to be admitted to an ICU, need mechanical ventilation, or die in comparison to non-smokers [6]. On the other hand, several other studies reported that smoking might protect against COVID-19, or at least, it might not be considered as a risk factor for vulnerability or severity $[7,8]$. The findings of these studies caused a shockwave among tobacco control organizations. Despite all these findings, tobacco is proven to cause 8 million deaths every year due to cardiovascular diseases, lung disorders, cancer, diabetes and hypertension; which has forced the World Health Organization (WHO) to question the correlation between smoking and severity of COVID-19 disease [9].

Taking into consideration that the use of shisha (water-pipe or narghile) has increased tremendously during the past few decades in Lebanon [10-12] and with a prevalence of $42.6 \%$ of smoking among the population aged 15 years or more in Lebanon [13], emerges a high need to study the effects of smoking on COVID-19-related outcomes in Lebanon. In the absence of information on smoking habits by individuals in the Lebanese population, some of whom could be or have been infected with COVID-19, we conducted a population-level questionnaire to collect information that may shed some light on whether cigarette 


\section{COVID-19 And Smoking: A Cross-Sectional Study Done In Lebanon}

or shisha smoking is associated with increased or decreased susceptibility to COVID-19 infection and development of COVID-19related symptoms.

\section{METHODS}

\subsection{Study design}

An online cross-sectional study was conducted in January 2021 using a random sample of 1642 participants from all Lebanese governorates (Beirut, Bekaa, Mount Lebanon, North and South).

\subsection{Data collection}

\subsubsection{Questionnaire}

A questionnaire adapted to the Arabic language was devised to help identify the participants' smoking habits and knowledge about COVID-19 in general. The survey included 24 close-ended questions using Google forms that was approved by the ethical committee at the Lebanese International University under the reference number LIUIRB-201210-ST1.

\subsubsection{Sample}

Respondents were divided into two groups: COVID-19 group and non-COVID-19 group. The first group (COVID-19 group) combined participants who either had previously been tested positive or who had been symptomatic for COVID-19. The second group (non-COVID-19 group) combined participants who had never been tested positive or who had never been symptomatic for COVID-19. The category of shisha smokers combined both "Moassal, a form of flavored tobacco that contains molasses and other additives" and tobacco-shisha smokers. Individuals were considered smokers if they currently smoke cigarettes, shisha, or e-cigarettes. Smokers were classified as heavy smokers if they consumed more than one packet of cigarettes (20 cigarettes) or more than one bowl of shisha; and non-heavy smokers if they consumed less [14].

\subsection{Statistical Analysis}

Data management was conducted using the Statistical Package for Social Science (SPSS) (IBM SPSS Statistics Version 23). For all analyses, P-value $<0.05$ was used to detect statistical difference.

\section{RESULTS}

A total of 1642 people, 1082 females and 560 males, participated in our cross-sectional study as is evident from table 1 . Participants were distributed among 4 age-groups: 217 were less than 20 years, 736 were aged 20 to 29 years, 363 were aged 30 to 39 years, and 321 were aged 40 and above. The participants were not restricted to any particular region of Lebanon and there were 558 from the Bekaa, 441 from the North, 347 from the South, 181 from Beirut, and 115 from Mount Lebanon. The grand majority of participants (958) had a university bachelor's degree, followed by 274 holders of a master degree or higher, 214 holders of a high school diploma, 140 who finished their intermediate education but did not enroll in a high school, and only 56 with below intermediate school education. The participants were distributed as 774 smokers and 868 non-smokers; 504 who at a certain point were diagnosed with COVID-19 or had the symptoms and 1138 who never tested positive and never exhibited any of the symptoms. COVID-19 patients were almost evenly distributed between smokers (258) and non-smokers (246).

Based on the results of our study, there was a clear difference between smokers and non-smokers with regards to their gender where $63 \%$ of the males were smokers $(p<0.001)$, while only $39 \%$ of the females smoked $(p<0.001)$. We did not detect any difference between the numbers of smokers and non-smokers in any of the age-groups except for the group aged 20 or less, in which the majority were non-smokers (66\% vs. $34 \%$; $<0.001)$. When looking into the different regions, participants from the Bekaa and the South were significantly more prone to smoking ( $p=0.005$ and $p<0.001$, respectively), while participants from the North exhibited a higher probability for not smoking $(p=0.007)$. Participants from Beirut and Mount Lebanon were equally as likely to smoke or not.

When looking at the incidence of COVID-19 with regards to age, we did not detect any differences among the 4 age groups. Even though the percentages of age-group 30-39 were almost identical to the other age-groups, we did not detect a significant difference between negative and positive cases within that group due to the small sample size.

Similarly, when looking at the incidence of COVID-19 with regards to the different regions, we did not detect any differences among the 5 regions. The small size of the Beirut sample is the likely reason why no difference was detected between negative and positive cases $(p=0.352)$. In addition, we did not detect any impact of the level of education on the probability of contracting COVID-19.

Interestingly, we did not detect any difference in the onset of COVID-19 between smokers and non-smokers across all agegroups; however, when we analyzed the different regions, it seemed that smokers from the South region exhibited a clear 


\section{COVID-19 And Smoking: A Cross-Sectional Study Done In Lebanon}

sensitivity to COVID-19 when compared to non-smokers (62\% vs. 38\%; $\mathrm{p}=0.027$ ); however, contradicting results were detected in the North region where COVID-19 cases were more prominent among non-smokers than smokers (62\% vs. $38 \%$; $p=0.001)$.

As evident from table 2, when we looked at the COVID-19 group and analyzed the severity of the symptoms with regards to smoking vs. non-smoking; shisha vs. cigarette; natural vs. artificial coal; heavy smoking vs. non-heavy smoking, we determined that smokers exhibited significantly more difficulty speaking and moving compared to non-smokers ( $p=0.019)$. Surprisingly, more smokers exhibited no symptoms when compared to non-smokers $(p=0.006)$. When comparing shisha smokers to cigarette smokers, shisha smokers exhibited more sever body pain $(p<0.001)$ and more difficulty speaking and moving $(p=0.011)$. When comparing shisha smokers that used natural coal as the burning agent versus artificial coal, artificial coal users exhibited a higher incidence of loss of taste or smell $(p=0.044)$. No differences were detected between heavy and non-heavy smoker groups.

We detected a shift in preference from cigarette smoking to shisha smoking among the younger generations of the Lebanese population (fig. 1). It was clear that the $40+$ age group had a preference for cigarette smoking $(61.2 \%$ vs. $38.8 \%$; $<<0.001$, $\mathrm{n}=147$ ), this preference gradually shifted in favor of shisha as the groups got younger. Age-group 30-39, $0.5 \%$ to $39.5 \%$ in favor of shisha ( $p=0.05, n=167$ ); age-group $20-29,78.7 \%$ to $21.3 \%$ in favor of shisha $(p<0.001, n=338$ ), and age-group $<20,76.2 \%$ to $23.8 \%$ in favor of shisha $(p=0.05, n=63)$.

\section{DISCUSSION}

At $47 \%$, the number of smokers in Lebanon is high in comparison to the USA (14\%) and Europe (28\%) [15-17]. This high percentage was consistent across all age groups that participated in the study. Participants aged 20 or less tended to smoke less younger smokers was still considerably higher than expected. It was also clear that smoking was more commonly practiced among males than females. We observed a region-related influence on the smoking tendency among our participants. Participants living in the Bekaa and the South were more likely to become smokers, while participants living in the North were more likely not to smoke. Participants living in Beirut and Mount Lebanon exhibited equal tendencies. It is not clear at this stage as to what the reason for this discrepancy is, but it is certainly something worth investigating.

Our study revealed that smoking was not a factor that increased susceptibility to COVID-19. The number of reported COVID-19 cases were identical between smokers and non-smokers. Also, we did not detect any effect of gender, education, region, or age on the likelihood of contracting the disease. However, smokers who contracted COVID-19 were more likely to develop speaking and moving difficulties compared to non-smokers.

A very large, nation-wide, study was done in the USA and it reported that people aged 20 to 49 were more likely to spread the COVID-19 infection [18]. In our study, the percentages of infected individuals in the age-groups $<20$ and $\geq 40$ seemed to be slightly below those of the other two age-groups. This could be attributed to two factors: First, during the time of the study, the schools were closed and participants in the age group below 20 years were mostly included in the lockdown and were less likely to interact with people other than their immediate families. Second, participants in the 40+ age group include individuals who are more likely to have underlying and chronic diseases and would therefore be more likely to take extra precautions, or are in their retirement age and their social interactions are less than other age groups.

When we looked into the smoker group of COVID-19 patients, we detected an increased likelihood of developing severe body pain and difficulty speaking and moving among shisha smokers when compared to cigarette smokers, which could be due to the difference in the composition of the tobacco and burning agents between cigarettes and shisha. When further analyzing the shisha-smokers group within the COVID-19 group, we detected an increased likelihood for losing the sense of taste and smell among those who used artificial coal rather than natural coal as the burning agent. These results did not provide conclusive evidence as to which agent in artificial coal was responsible for the loss of taste and smell since some types of artificial coal used by shisha smokers may contain chemical binder and ignition agents and release higher levels of polycyclic aromatic hydrocarbons $\mathrm{PAH}[15]$.

Looking at symptom development in COVID-19 patients, we find that 40-45\% remain asymptomatic [19]. Cough and chest pain are common symptoms among regular smokers and COVID-19 patients alike [20-22]. which could explain why more COVID-19 patients who smoked were more likely to report being asymptomatic. These results conform with the results of a French study reporting that active smokers have a lower probability of developing severe symptoms of COVID-19 [7]. 
Table 1: Summary of Questionnaire Responses Based on Socio-demographics (Jan, 2021)

\begin{tabular}{|c|c|c|c|c|c|c|c|c|c|c|}
\hline & \multicolumn{4}{|c|}{ Smoker } & \multicolumn{2}{|c|}{ COVID-19 } & \multicolumn{3}{|c|}{ COVID-19 } & \multirow[b]{2}{*}{$p$} \\
\hline & Total & No & Yes & $p$ & Non-smoker & Smoker & $p$ & Yes & No & \\
\hline & $(\mathrm{N})$ & $(\mathrm{n} .868)$ & (n.774) & & (n.246) & $(\mathrm{n} .258)$ & & (n.504) & (n.1138) & \\
\hline & & $\%$ & $\%$ & & $\%$ & $\%$ & & $\%$ & $\%$ & \\
\hline Total & 1642 & 53 & 47 & & 49 & 51 & & 31 & 69 & \\
\hline \multicolumn{11}{|l|}{ Gender } \\
\hline male & 560 & 37 & 63 & $<0.001^{*}$ & 36 & 64 & $<0.001^{*}$ & 33 & 67 & 0.172 \\
\hline Female & 1082 & 61 & 39 & $<0.001^{*}$ & 56 & 44 & $<0.001^{*}$ & 30 & 70 & 0.172 \\
\hline \multicolumn{11}{|l|}{ Age Group } \\
\hline$<20$ & 217 & 66 & 34 & $<0.001^{*}$ & 60 & 40 & 0.100 & 24 & 76 & $0.021^{*}$ \\
\hline $20-29$ & 736 & 52 & 48 & 0.423 & 46 & 54 & 0.189 & 36 & 64 & $<0.001^{*}$ \\
\hline $30-39$ & 363 & 49 & 51 & 0.098 & 48 & 52 & 0.877 & 30 & 70 & 0.659 \\
\hline$>40$ & 321 & 50 & 50 & 0.279 & 50 & 50 & 0.819 & 24 & 76 & $0.006^{*}$ \\
\hline \multicolumn{11}{|l|}{ Region } \\
\hline Beirut & 181 & 49 & 51 & 0.292 & 51 & 49 & 0.738 & 34 & 66 & 0.352 \\
\hline Bekaa & 558 & 48 & 52 & $0.005^{*}$ & 46 & 54 & 0.284 & 39 & 61 & $<0.001^{*}$ \\
\hline Mount Lebanon & 115 & 53 & 47 & 0.968 & 43 & 57 & 0.577 & 18 & 82 & $0.003^{*}$ \\
\hline North & 441 & 66 & 34 & $<0.001^{*}$ & 62 & 38 & $0.001^{*}$ & 27 & 73 & $0.036^{*}$ \\
\hline South & 347 & 46 & 54 & $0.007^{*}$ & 38 & 62 & $0.027^{*}$ & 26 & 74 & $0.022^{*}$ \\
\hline \multicolumn{11}{|l|}{ Level of Education } \\
\hline $\begin{array}{l}\text { Non-educated- } \\
\text { Elementary }\end{array}$ & 56 & 55 & 45 & 0.703 & 55 & 45 & 0.700 & 20 & 80 & 0.068 \\
\hline Intermediate & 140 & 50 & 50 & 0.478 & 33 & 67 & 0.080 & 21 & 79 & $0.013^{*}$ \\
\hline Secondary & 214 & 48 & 52 & 0.102 & 40 & 60 & 0.189 & 23 & 77 & $0.013^{*}$ \\
\hline Bachelor's Degree & 958 & 54 & 46 & 0.447 & 50 & 50 & 0.438 & 33 & 67 & $0.040^{*}$ \\
\hline Master's degree & 274 & 55 & 45 & 0.414 & 53 & 47 & 0.349 & 36 & 64 & $0.023^{*}$ \\
\hline
\end{tabular}

* highlighting significant p values.

Table 2: Summary of Questionnaire Responses discussing COVID-19 group experienced symptoms (Jan, 2021)

\begin{tabular}{|c|c|c|c|c|c|c|c|c|c|c|c|c|}
\hline Symptoms & $\begin{array}{c}\text { Smoke } \\
\mathbf{r}\end{array}$ & $\begin{array}{l}\text { Non- } \\
\text { smoker }\end{array}$ & $p$ & $\begin{array}{l}\text { Shisha } \\
\text { smoker }\end{array}$ & $\begin{array}{l}\text { Cigarette } \\
\text { smoker }\end{array}$ & $p$ & $\begin{array}{c}\text { Natural } \\
\text { coal }\end{array}$ & $\begin{array}{c}\text { Artificial } \\
\text { Coal }\end{array}$ & $p$ & $\begin{array}{l}\text { Heavy } \\
\text { smoker }\end{array}$ & $\begin{array}{l}\text { Non- } \\
\text { Heavy } \\
\text { smoker }\end{array}$ & $p$ \\
\hline & $\mathrm{n}=258$ & $\mathrm{n}=246$ & & $\mathrm{n}=170$ & $n=64$ & & $n=46$ & $\mathrm{n}=124$ & & $\mathrm{n}=93$ & $\mathrm{n}=141$ & \\
\hline & $\%$ & $\%$ & & $\%$ & $\%$ & & $\%$ & $\%$ & & $\%$ & $\%$ & \\
\hline Chest pain & 27.13 & 29.67 & 0.915 & 30 & 29.69 & 0.915 & 23.91 & 32.26 & 0.263 & 35.48 & 26.24 & 0.131 \\
\hline Diarrhea & 21.32 & 24.8 & 0.901 & 25.88 & 17.19 & 0.144 & 32.61 & 23.39 & 0.257 & 26.88 & 21.28 & 0.322 \\
\hline Dry cough & 34.88 & 46.75 & 0.112 & 41.18 & 31.25 & 0.15 & 32.61 & 44.35 & 0.151 & 33.33 & 41.84 & 0.19 \\
\hline Itching and pain & 14.73 & 12.6 & 0.166 & 11.76 & 14.06 & 0.46 & 19.57 & 16.13 & 0.767 & 12.9 & 18.44 & 0.37 \\
\hline $\begin{array}{l}\text { Severe body } \\
\text { pain }\end{array}$ & 46.51 & 46.34 & 0.141 & 58.24 & 32.81 & $<0.001$ & 54.35 & 59.68 & 0.506 & 58.06 & 46.81 & 0.092 \\
\hline $\begin{array}{l}\text { Speaking and } \\
\text { moving } \\
\text { difficulty }\end{array}$ & 19.77 & 14.63 & $0.019^{*}$ & 25.88 & 10.94 & $0.011^{*}$ & 17.39 & 29.03 & 0.108 & 26.88 & 18.44 & 0.126 \\
\hline $\begin{array}{l}\text { Difficulty } \\
\text { Breathing }\end{array}$ & 22.87 & 28.46 & 0.578 & 26.47 & 21.88 & 0.432 & 26.09 & 26.61 & 0.884 & 27.96 & 23.4 & 0.433 \\
\hline Fever & 36.82 & 50.41 & 0.106 & 42.94 & 34.38 & 0.217 & 43.48 & 42.74 & 0.974 & 43.01 & 39.01 & 0.542 \\
\hline $\begin{array}{l}\text { Loss of } \\
\text { smell or } \\
\text { taste }\end{array}$ & 56.98 & 63.41 & 0.948 & 64.12 & 59.38 & 0.484 & 52.17 & 68.55 & $0.044^{*}$ & 63.44 & 62.41 & 0.873 \\
\hline Backache & 5.04 & 9.35 & 0.182 & 5.29 & 6.25 & 0.908 & 2.17 & 6.45 & 0.214 & 4.3 & 6.38 & 0.496 \\
\hline $\begin{array}{l}\text { No } \\
\text { symptoms }\end{array}$ & 11.63 & 4.88 & $0.006^{*}$ & 11.18 & 17.19 & 0.214 & 17.39 & 8.87 & 0.113 & 11.83 & 13.48 & 0.712 \\
\hline
\end{tabular}


(34\%), however the ratio of these

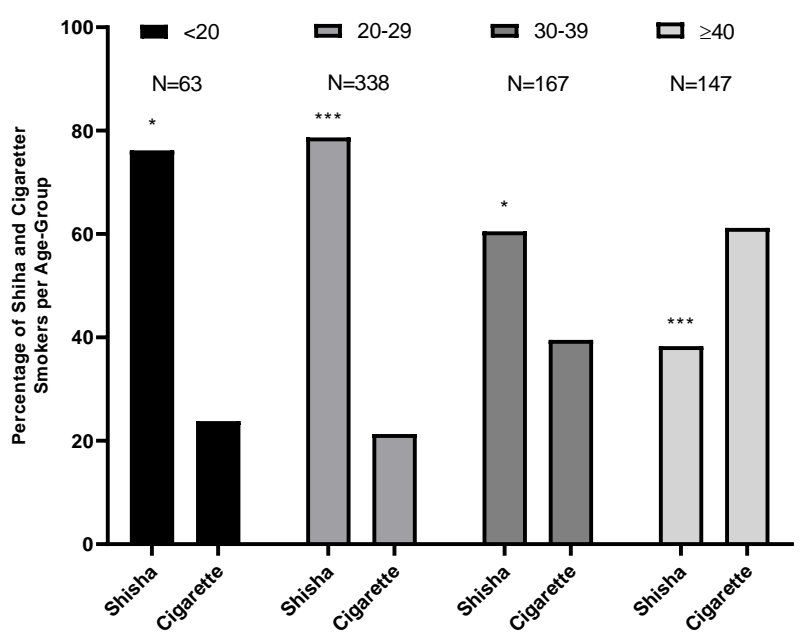

Figure 1. A comparison between Shisha and Cigarette smokers among the different age groups.

$* \mathrm{p}<0.05$ and $* * * \mathrm{p}<0.001$.

\section{CONCLUSION}

According to our study shisha smoking and the use of artificial coal have a significant impact on the accentuation of certain COVID-19 symptoms. This will most likely hold true for the symptoms of other respiratory pathogens that might be the cause of future pandemics. The ratio of smokers in Lebanon is alarmingly high, and the tendency of the younger generations to smoke shisha is even more alarming. Combining our findings that shisha smokers are more likely to develop severe symptoms of respiratory diseases and the increased preference of the younger generations to smoke shisha, this means that the population will be at a higher risk of life-threatening complications that could result from the emergence of any future respiratory pathogen endemic or pandemic. This is something that needs to be addressed publicly through awareness campaigns and other organized activities.

\section{CONFLICT OF INTEREST}

The authors declare no conflict of interest, financial or otherwise.

\section{ACKNOWLEDGEMENTS}

The authors thank all those who participated in this study.

\section{REFERENCES}

1) Corona Virus. Lebanese Ministry of Information website; 2021 [updated 5 Apr 2021; cited 5 Apr 2021]; Available from: https://corona.ministryinfo.gov.lb

2) Lowe KE, Zein J, Hatipoglu U, Attaway A. Association of Smoking and Cumulative Pack-Year Exposure With COVID-19 Outcomes in the Cleveland Clinic COVID-19 Registry. JAMA Intern Med. 2021 Jan 25:e208360.

3) Zhao $Q$, Meng $M$, Kumar $R$, Wu $Y$, Huang J, Lian $N$ et al. The impact of COPD and smoking history on the severity of COVID-19: A systemic review and meta-analysis. J Med Virol. 2020; 92(10):1915-1921

4) Russo P, Bonassi S, Giacconi R, Malavolta M, Tomino C, Maggi F. COVID-19 and smoking: is nicotine the hidden link? Eur Respir J. 2020; 55(6): 2001116.

5) Gaiha SM, Cheng J, Halpern-Felsher B. Association Between Youth Smoking, Electronic Cigarette Use, and COVID-19. J Adolesc Health. 2020; 67(4): 519-523.

6) Vardavas $\mathrm{Cl}$, Nikitara K. COVID-19 and smoking: A systematic review of the evidence. Tob Induc Dis. 2020; 18(20): 1-4

7) Miyara, M., Tubach, F., Pourcher, V., Morelot-Panzini, C., Pernet, J., Haroche, J., et al. Low incidence of daily active tobacco smoking in patients with symptomatic COVID-19. Qeios. 2020; doi:10.32388/WPP19W.3

8) Li, M., Zhang, Z., Cao, W., Liu, Y., Du, B., Chen, C. et al. Identifying novel factors associated with COVID-19 transmission and fatality using the machine learning approach. Sci Total Environ. 2021; 764: 142810. 


\section{COVID-19 And Smoking: A Cross-Sectional Study Done In Lebanon}

9) Smoking and COVID-19. WHO website; June, 2020 [cited 20 Mar 2021]; Available from: https://www.who.int/newsroom/commentaries/detail/smoking-and-covid-19

10) Chaaya M, El-Roueiheb Z, Chemaitelly H, Azar G, Nasr J, Al-Sahab B. Argileh smoking among university students: a new tobacco epidemic. Nicotine Tob Res. 2004; 6(3): 457-463.

11) Tamim, H., Al-Sahab, B., Akkary, G., Ghanem, M., Tamim, N., El Roueiheb, Z.et al. Cigarette and nargileh smoking practices among school students in Beirut, Lebanon. Am J Health Behav. 2007; 31(1): 56-63.

12) Nakkash RT, Khalil J, Afifi RA. The rise in narghile (shisha, hookah) waterpipe tobacco smoking: a qualitative study of perceptions of smokers and non-smokers. BMC Public Health. 2011; 11: 315.

13) Report on the global tobacco epidemic. WHO website; 2020 [cited 20 Mar 2021]; Available from: https://www.who.int/teams/health-promotion/tobacco-control/who-report-on-the-global-tobacco-epidemic-2019

14) Kaleta D, Makowiec-Dąbrowska T, Dziankowska-Zaborszczyk E, Fronczak A. Determinants of heavy smoking: results from the global adult tobacco survey in Poland (2009-2010). Int J Occup Med Environ Health. 2012; 25(1): 66-79

15) Burden of Cigarette Use in the U.S. Centers for Disease Control and Prevention. CDC website; 2019 [cited 12 Mar 2021]; Available from: https://www.cdc.gov/tobacco

16) European tobacco use. WHO website; 2019 [cited 12 Mar 2021]; Available from: https://www.euro.who.int

17) Smoking and tobacco use. CDC website; 2019 [cited 12 Mar 2021]; Available from: https://www.cdc.gov/tobacco

18) Monod, M., Blenkinsop, A., Xi, X., Hebert, D., Bershan, S., Tietze, S., et al. (2021). Age groups that sustain resurging COVID-19 epidemics in the United States. Science. 2021; 371(6536): eabe8372.

19) Oran DP, Topol EJ. Prevalence of Asymptomatic SARS-CoV-2 Infection: A Narrative Review. Ann Intern Med. 2020; 173(5): 362-367.

20) Grace M.S., Birrell M.A., Dubuis E., Belvisi M.G. Tobacco smoke induced cough: mechanisms driving acute and chronic cough pathology. In: Moldoveanu A.M., editor. Advanced topics in environmental health and air pollution case studies. 2nd ed. In Tech; 2011. pp. 97-120.

21) Friedman GD, Siegelaub AB, Dales LG. Cigarette smoking and chest pain. Ann Intern Med. 1975; 83(1): 1-7.

22) Symptoms, spread and other essential information about coronavirus and COVID-19. Harvard Medical School website; 2021 [cited 17 Feb 2021]; Available from: https://www.health.harvard.edu/diseases-and-conditions/covid-19-basics 